\title{
CIEN AÑOS DE SOLEDAD: REALISMO BELGA EN LO MARAVILLOSO
}

\author{
Víctor Valembois \\ Universidad de Costa Rica \\ Universidad Nacional
}

Universo es palabra admirable, suma de toda filosofía: lo uno en lo diverso, lo diverso en lo uno. José Martí.

\section{El binomio universal-local y su actual vivencia de lo global}

Ciudadano del mundo, como uno trata de ser (vieja receta de Brenes Mesén ${ }^{1}$, ideal para tiempos de globalización), a veces pienso que a Bélgica le haría falta un toque de lo mágico tropical a lo García Márquez. Dichosos los personajes de Cien años de soledad que también del otro lado del Atlántico adquieren vida, porque si bien no procede confundir el Orinoco con el Sena o el Rin, por allá también se encuentra más de una Ursula, además de otros descendientes de la estirpe de los Buendía. Y soledad no falta. Claro, la medicina al revés tampoco caería mal por estos lares.

Hay sorprendentes reminiscencias belgas en la literatura centroamericana, como ya queda plasmado a partir de investigaciones mías sobre los nicaragüenses Darío, Pallais y de la Selva². Más al sur,

1. El poeta muy costarricense (1874-1947) tiene un poema «Mi Patria» en el que insistentemente se declara «ciudadano del mundo». Como él mismo lo reconoce, se trata por cierto de una paráfrasis inspirada en el muy europeo Schiller.

2. Sobre cada uno de estos autores tengo escritos unos «avances de investigación», publicados por el Programa de Identidad de la Facultad de Letras, en la Universidad de Costa Rica, 1997. 
constan interferencias de este tipo en Benedetti ${ }^{3}$, en Cortázar ${ }^{4}$, o acercándonos ya a riberas colombianas, en Alvaro Mutis ${ }^{5}$. En la citada novela de «Gabo", como se le conoce familiarmente, se rastrea una gran cantidad de alusiones que no por anecdóticas en apariencia resultan irrelevantes. La tesis desarrollada aquí es que estas alusiones más bien adquieren una profunda razón de ser y se enmarcan dentro del proceso de creación de lo real maravilloso. A partir de la ubicación de coincidencias entre la novela y mi país (puntos 2 y 3 ), procederé a unas reflexiones deductivas, primero sobre el hecho de que no hay azar sino circunstancia (punto 4) y segundo sobre la relación literatura-historia (punto 5). En este Macondo, (¿epónimo de la aldea global que nos espera?) el resultado queda en el limbo entre realidad y ficción, una mezcla, llamada lo «real maravilloso», de la que en todas partes necesitamos una ración.

\section{Macondo amueblado con bicicleta belga $y$ un flamenco extravagante}

En un lugar mítico de cuyo nombre sí conviene acordarse, en San José como en Bruselas, poco menos que todo resultó importado, empezando por la máquina de hacer hielo qứe «muchos años después, frente el pelotón de fusilamiento (...) había de recordar» el coronel Aureliano Buendía ${ }^{6}$. Como narra García Márquez al principio de este auténtico Quijote del Siglo XX, varios portentos tecnológicos los

3. Biografía de Mario Benedetti escrita por Mario Paoletti, El aguafiestas (Alfaguara, Santillana, 1996, 267 pp.). En la p. 26 se menciona «la estancia Santa Blanca, del tamaño de una provincia belga», referencia totalmente pasajera, la verdad.

4. El muy argentino nació en Bruselas y vivió años en París, guardando un acento increíblemente francés en su pronunciación española.5. Las interfe rencias entre este autor y Bélgica son sutiles. Convendría hacer un estudio específico al respecto, interno a la obra. En el presente ensayo se desarrolla algo la relación Mutis - Bélgica, pero por el lado hiográfico, externo a su creación.

6. A partir de aquí, las referencias explícitas o no (entrecomilladas las primeras) se citarán por la edición de Isspasa Calpe, Madrid, 1983. 
trajeron los gitanos, el imán por ejemplo. Siendo la música consustancial a este grupo humano, «todos los años, por el mes de marzo» llegaban aquellos «con un gran alboroto de pitos y timbales» al pueblo fantasmagórico. Melquíades era uno de ellos, aunque le conocemos más destreza en las genealogías diabólicas que en la música flamenca. La obra empieza con este grupo de forasteros ruidosos que se iban al rato. Pero casi al terminar la novela irrumpe en escena otro extranjero, sólo y para quedarse varios años. Llega igual, con un armatoste tecnológico, casualmente también otra interferencia flamenca, tomando esta vez el término en sentido original, es decir, de Flandes ${ }^{7}$.

Se trata, nada menos, de una bicicleta Made in Belgium de veras exótica en estos parajes subtropicales. Se describe con lujo de detalles. Se trata de un «biplano deportivo». No es un portento cualquiera, sino «aparatoso», porque tenía la «rueda anterior mucho más grande que la posterior». Pero por otro lado, se «desarmaba dentro de un estuche especial que permitía llevarlo como un violoncelo». Mundo global se llama eso: un belga extraviado en Macondo y con «una bicicleta de circo» del otro lado del Atlántico. El narrador le pone «Gastón» como nombre al individuo en cuestión. No se señala el apellido del ingenioso, ya no hidalgo sino «motorista». Pero se describe con cierto goce pintoresco como «flamenco, maduro, esbelto y con aires de navegante». Era adinerado por familia, porque ésta tenía inversiones en aceite de palma en el Congo belga.

Por gracia del prestidigitador verbal que es Gabo este nórdico aparece un día en Macondo —o San José o Madrid, si le damos al

7. El gentilicio «flamenco» proviene originalmente de Flandes. En el año 1500 nacióen Gante el que sería Carlos V de los Habsburgos y I de España. En un anticipo del choque cultural Norte-Sur, este y sus súbditos no caían muy bien en España, por diferencias de idioma y de costumbres. En el español del siglo XVI se llegó a asociar el término con extraño y gente de mal vivir. Después, en una segunda desviación, se relacionó con otro grupo igual, en esta supuesta categoría: los gitanos de Andalucía. Hoy, a nivel internacional se asocia más espontáneamente con la expresión musical de estos. No hay sino coincidencia con «flamenco», el nombre de cierto pájaro. 
topónimo su justo valor metafórico- como esposo de Amaranta Ursula, bisnieta del Coronel Aureliano Buendía. Llegó «amarrado por el cuello con un cordel de seda». El trasplantado era cuarentón y de hábitos «cautelosos». En realidad se entretenía en prácticas investigativas bastante atrevidas y extravagantes, tanto allá, cuando se conocieron, como después, durante su estadía prolongada en Macondo. Muchos otros aspectos de él se revelan a lo largo de las páginas evocadas, como que era un hombre muy.deportivo y emprendedor. Es un flamenco típico, bueno para comer (con un «hígado colonial»), hábil para aprender el castellano, amante de los canarios y desprendido de su tierra hasta como para ir a «las islas Afortunadas» ${ }^{8}$. Otro detalle: cuando andaba en el velocípedo usaba «pantalones de acróbata, medias de gaitero y cachucha de detective». Por Dios, ¡qué cuadro! Sólo un loco, de nombre hispanizado Bosco, en realidad el flamenco Bosch, podía anticiparse en mezcla de elementos de lo real maravillo al estilo de Gabo. El primero con sus pinceles, el segundo con la palabra, ambos captarían evocaciones muy de su tierra. Pero los dos trascienden espacio y tiempo, para formar parte del patrimonio de toda la humanidad.

\section{Estudiosos y amorosos, en Bélgica y después en Macondo}

Ahora bien, el «navegante» trasatlántico sobre dos ruedas había hecho estudios avanzados en entomología en la Universidad de Lieja, Bélgica y guardó de allí un acervado espíritu de interrogación científica. Aparte del enamoramiento loco y el esperpéntico dogal de seda — verdadero leitmotiv burlesco para visualizar el carácter bonachón

8. Nombre de las Islas Canarias «de las que ya se hablaba desde la Antigüedad y en las que decían se encontraban los Campos Eliseos de Homero", cito por María Rosa de Madariaga in l:I mundo árabe en América Latina (UNESCO: 1997) 41. ¿Sabrá García Márquez que en estas islas y sobre todo en las Azores hubo mucha influencia flamenca (original, de lilandes), por vínculos dinásticos medievales? 
del flamenco-con el que Amaranta Ursula lo tenía amarrado, fue este talento el que lo hizo cruzar su Rubicón: «para ser pionero daba lo mismo el Caribe que el Africa». Como los esposos habían hecho un pacto de no tener niños en los primeros cinco años, se dedicó todo este tiempo a leer, a escribir, a disecar y a estudiar las posibilidades del correo por aeroplano. Se trata de un ejemplar exalumno, porque durante toda su permanencia en el exterior, Gastón no sólo mantendrá contacto epistolar con su universidad de origen, sino que guardará un noble espíritu de investigador en cuanta aplicación se le pusiera por delante. Lo cierto es que fue aplicando este talento como conoció a su mujer.

La casualidad quiso que ella, habitante del fantástico Macondo, también había estudiado en Bélgica, sólo que en la capital, a unos cien kilómetros de Lieja. Resulta curioso como el narrador se atrasa cantidad de veces en aspectos de estudio y de desempeño profesional de Gastón; en cambio ni una palabra sugiere al respecto, para su consorte. No queda dicho qué estudió ella, pero se deduce que no es a nivel universitario. Prevalece un cierto misterio en el caso, primero al corroborar que una mujer tiene oportunidad de estudiar al otro lado del Océano, cosa destacadísima para los tiempos aludidos. Luego, el narrador aumenta la intriga al señalar que «Amaranta Ursula (...) mandó decir que sus estudios se prolongaban más tiempo del previsto, porque sus excelentes calificaciones le habían merecido privilegios que su padre no tomó en consideración al hacer las cuentas.» No se sabe a qué reconocimiento se alude. Podría tratarse de algún beneficio económico en forma de beca, quizá. Total que se quedaría más de tres años.

Una vez de regreso, a diferencia de su marido, no consta que le haya sacado mucho provecho a su formación. Se deduce de todo quc después de «manifestar buen juicio y una consagración a los estudios» (a principios de la secundaria) el padre optara por of recerle un barni\%. cultural en el exterior, cosa de que regresara, como efectivamenlc lo hizo, no tanto con un título útil, sino con un buen marido. Iin clicll. «le había prometido mandarla a terminar sus estudios en Brusclils, dl. acuerdo con una costumbre establecida en los ticmpos de la compinillil 
bananera.» Pero allí, a la niña le dio la nostalgia; lo tenía todo bien organizado, hasta cómo se llamarían sus futuros hijos. Tal como la tira cómica de Mafalda, un registro artístico muy diferente, claro, diríamos que se trata de una Susanita cualquiera que estudia en espera de casarse. Amaranta y Gastón se formaron en Bélgica, pero el perfil de estudio de los dos no puede ser más opuesto.

Pero no todo es academia. Vale que el enlace entre Bélgica y Macondo también es amoroso. Entre Amaranta Ursula y su progenitor había prevalecido un vínculo entre cursi y tierno: ella se despediría de él entre un paso de baile y «con la punta de los dedos en un beso de despedida». Su relación con el flamenco sería bastante más impetuosa y explícita, tanto a quinientos metros de altura bajo el cielo de Bruselas, como después en forma más pedestre en el subtrópico. Gastón asumió también el papel de protector con su amada, igual que su suegro, no sólo por llevarle como quince años, sino por una cuestión de temperamento. Contrastaban el desenfreno y el ímpetu de Amaranta y el tranquilo equilibrio del flamenco. Pero su amor terminó en fracaso, por una total desaveniencia en la visión del mundo, en profundidad, más allá de la atracción de momento. El cartesianismo y la mitología ancestral tipo Buendía resultan irreconciliables.

Gastón no podía negar sus raíces culturales, incluyendo una percepción lineal del tiempo. En la vida profesional y en sus ocupaciones confiaba en el progreso, con el sentimiento positivista de que lograría disecar y desentrañar los misterios de su nuevo entorno como salir adelante con sus proyectos de correo aéreo. También en el amor confiaba en el dios Cronos, con una fe racional. Se dejó convencer de ir a vivir a Macondo porque «como (...) con el sedal, (...) creyó que era un capricho transitorio ...» En cambio Amaranta, de la estirpe de los Buendía, vivía en un tiempo circular y reiteró su decisión de no moverse de Macondo «aunque se quedara sin marido». Aquello de «me voy a Bélgica en el primer barco que salga» era puro arranque e impulso que no se llevaría a cabo. La mansedumbre de Gastón llegaría al colmo cuando ella le adornó la frente, en la típica «soledad», como 
la entiende el genial creador de esta novela del mismo nombre. El desenfreno amoroso la llevaría a la muerte. En cambio el macho finalmente se resolvió por regresar a Bruselas por sus asuntos comerciales. Desde allí «tranquilo, casi paternal» mandó consejos a los amantes «para prevenirlos contra las veleidades de la pasión, y un párrafo final con votos inequívocos por que fueran tan felices como él lo fue en su breve experiencia conyugal.»

García Márquez no sería maestro si todo aquello no lo describiera con su pluma fantástica, más allá de recovecos literarios y desvíos momentáneos. Todo queda amarrado en un tejido donde no sobra ni falta un hilito narrativo, por más fantasmagórico que pareciera. Casi al terminar el relato sitúa al flamenco en Leopoldville (capital del entonces Congo belga). Es cuando presenciamos la estocada final para un enlace de este fallido «encuentro de dos mundos»: Gastón, conocido en el pueblo de Amaranta bajo la «idea generalizada» de ser «un tonto en velocípedo», escribe una última carta «sólo para pedir que (se lo) mandaran, que de todo lo que había dejado en Macondo era lo único que tenía para él un valor sentimental». Hasta aquí, la reconstrucción de las interferencias belgas en la novela, respetando estrictamente la información proporcionada por el narrador omnisciente.

\section{De la creación literaria, retrocediendo a las fuentes reales}

«El azar y la necesidad» es un ensayo en el campo de la biología 9. A partir de un sugerente título, plantea que en la naturaleza nada resulta fortuito. La pretendida suerte obedecería a un designio escondido. Algo por el estilo pasa en este caso en la peligrosa intersección entre novela y fuentes reales, entre otros la propia biografía de su autor. Me doy cuenta del salto mortal, porque la vida y la obra literaria pertenecen a dos órbitas distintas. Sin embargo, es demasiado fuerte la

9. El volumen original Le hasard et la nécessité, de Jacques Monod, fue traducido al castellano: El azar y la necesidad (Barcelona, Seix Barral: 1975. 
sugerencia metodológica a partir de la hipótesis científica aludida. De ahora en adelante pasaré a una lectura creativa de Cien años de soledad, desde la óptica de otro flamenco trasplantado al sur del Nuevo Mundo. García Márquez verá si escucha o no: ¿no decían Michelet(en Europa) y Cortázar (para América Latina) que ha llegado la hora del lector? ${ }^{10}$

Esta novela no pretende ser catalogada como «histórica» y es peligroso relacionar en todos sus extremos una obra de arte con la biografía de una persona o un pueblo. Igual pasa con el Quijote: extrapolar datos objetivos de la vida en España hace casi cuatro siglos a partir de lo narrado puede resultar sugerente, pero conviene hacerlo con sumo cuidado. Por de pronto no estoy postulando relaciones de causa a efecto entre realidad y ficción, en términos absolutos. Sí observo coincidencias sorprendentes entre, por un lado, un espíritu que marcó realmente determinado momento histórico en un país específico, y por otro lado, eso mismo presentado simbólicamente en determinada creación imaginaria. Por lo demás nadie discute que el arte es eso,... artificio, artificial.

En el caso de las simpáticas interferencias belgas en la novela colombiana, la hipótesis más fácil consiste en especular con una simple coincidencia. Es cierto, su creador lo mismo habría podido desarrollar su genial metáfora acerca de la manera de ser y de pensar de su tierra y de su subcontinente, en confrontación con el progreso y los elementos exteriores, inventando amores de una chica de por allá con un mozuelo japonés vestido con kimono en Macondo... Pero el porfiado hecho es que se inclinó por demostrar el choque cultural y la consecuente abulia y alienación de su gente, entre otros a partir del encuentro con un europeo, y no cualquiera. En lo diacrónico, habría podido situar su tinglado de la imaginación en época de la Colonia, pero prefirió describir un proceso evolutivo que arranca un para atrás,

11). (ial)ricl ( iarcíiı Márquez, ('ie'n años de soledad (Madrid, Espasa Calpe: 1983). Desde

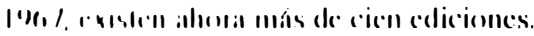


cosa de desembocar en lo contemporáneo. Si no es realidad, tiene un algo, tan palpable e inmediato, que forma parte del encanto universal y clásico de su obra, en América Latina, en Japón, como en Europa. El ejercicio virtual se transforma en imagen iluminadora. El arte tiene doble y triple filo y penetra hasta el alma.

En el norte colombiano real de la segunda mitad del siglo XIX, casi por fuerza el progreso venía de fuera y condicionado por su orientación física hacia el Caribe además de vínculos históricos con Europa. Después vinieron el capital norteamericano y la compañía bananera. Pero antes y hasta hace unas décadas prevalecía el Viejo Continente. De allí que, en la novela, florece sobre cierta percepción de la realidad de siempre y su cambio por la llegada de lo externo. El yo se descubre en el encuentro con el otro. No sorprende encontrar inmigrantes de toda índole y calaña, entre otros catalanes y franceses. Caso típico sería el trágico médico galo que aparece en este relato como en La Hojarasca. Hay otras referencias únicamente occidentales, pero diversas, desperdigadas en la novela, mediante personajes y alusiones literarias (como Horacio, Rabelais o Milton, ...). Pero es a Bélgica que más se alude. ¿Simple encadenamiento de casualidades (el «azar») o hecho comprobable en la vida real (la «necesidad»)?

«Muchos años después», ante el acoso periodístico, García Márquez reconocería que el don del verbo le vino, no por estudios en una universidad belga, sino a raíz de un memorable encontronazo que tuvo, en su juventud, con... una bicicleta. El cura que lo levantó le gritó justo a tiempo «¡cuidado!» Después le explicó que menos mal que le había vociferado; que eso probaba «la fuerza de la palabra». No me consta si el entonces pobre aspirante a novelista se dio de bruces con un velocípedo belga, modelo similar al impactado por su futura creatura. Lo cierto es que desde entonces quedó chocado en su prodigiosa imaginación artística, como para transportar un artefacto biplano desde la tierra del surrealista Bosco al realismo maravilloso de Macondo.

Pero eso no es todo. A propósito del premio Príncipe Asturias de las Letras otorgado en 1977 a su amigo Alvaro Mutis, viejo compañero 
de La Cueva de Barranquilla, el Nóbel cuenta otro enredo sobre dos ruedas. Era en tiempos de sus andanzas europeas, entre otros en tierras de Flandes, juntos en 1954. Dice así: «la enseñanza más enigmática de aquellos viajes frenéticos fue a través de la campiña belga, enrarecida por la bruma de octubre y el olor de caca humana de los barbechos recién abandonados. Alvaro había manejado durante más de tres horas, aunque nadie lo crea, en absoluto silencio. De pronto dijo: «país de grandes ciclistas» ${ }^{11}$. Sale a relucir entonces que Gabo, en Colombia y en Bélgica sucumbió a lo que Roland Barthes llama la «fascinación por la bicicleta» ${ }^{12}$. Pero además, en esta andanza tiene un alma gemela, en la persona de su colega novelista, otro prendido del velocípedo de por allá y por acá.

La coincidencia entre realidad y ficción se evidencia más todavía si se confronta lo narrado con una serie de hechos comprobados de relación de estudios entre Colombia y Bélgica. Sobre todo antes de la gran crisis del 29, los de la juventud de Gabo, eran muchos los compatriotas suyos que iban a estudiar a Europa, sobre todo a Bélgica. El caso epónime quizá es el del mismo expresidente López Michelsen. Cantidad de profesionales de esta generación sacaron su carrera en Lovaina, Lieja, Gante, Gembloux y Bruselas. Después del conflicto bélico la corriente disminuiría, pero se mantendría fuerte, como en caso de otro colombiano latinoamericanista, sacerdote y guerrillero, discípulo tardío del Cardenal Mercier, de nombre Camilo Torres. El mismo Alvaro Mutis aludido cursó la primaria en Bruselas. Por cierto, y que me perdone el nexo, Helena Ospina, poetisa colombiana radicada en Costa Rica, se me parece tremendamente al personaje de

11. Ver el artículo «Mi amigo Mutis», escrito por el mismo García Márquez en $A B C$ (Madrid, 26 de abril de 1997) 61. Nacido en 1923 y por tanto totalmente de la misma generación que Gabo, Alvaro Mutis estuvo un buen número de años en Bélgica, sobre todo entre la capital y Amberes, e hizo la primaria en Bruselas. Por tanto, en una nueva coincidencia entre ficción y realidad, también se parece a Amaranta Ursula, en Cien arios de soledad.

12. Del original Mythologies, existe traducción española, Mitologías. Ver también el artículo “l a bicicleta», de Vicente Verdú en El País (Madrid, 19 de julio 1997). 
Amaranta Ursula en ciertos aspectos (felizmente no en otros), porque las dos fueron enviadas a Bélgica, concretamente a la misma capital, a terminar la secundaria y alojaron en sendas pensiones regidas por religiosas. No ajeno a todo esto está la influencia y hasta la presencia en tierra colombiana del pedagogo belga Ovide Decroly fallecido en $1932^{13}$.

El azar que viene a ser necesidad, se fortalece si se compara lo anterior con una relación intercontinental muy parecida respecto de Costa Rica. El expresidente Calderón Guardia sería el equivalente de López Michelsen. Pero ellos no son sino los epígonos de todo un fenómeno generacional: hay constancia registral de más de ochenta costarricenses estudiando en Bélgica en estos mismos años veinte de la realidad ${ }^{14} \ldots$ y de la novela. Sobre todo Bruselas tenía buena fama, a pesar de que estuviera «tan cerca de la perdición de París», como argumentaba la madre de Amaranta Ursula. En cambio a Roma iban los que, por razones académicas y climatológicas, no se la podían en Bélgica $^{15}$, como en el caso, se supone, de José Arcadio Buendía. Por cierto que en su magistral historia de la influencia extranjera en Costa Rica, Luis Felipe González apunta la presencia en estas tierras de un mismo tipo de investigador belga como lo fue Gastón en Macondo: el europeo vino a estas tierras con un afán de catalogar, de describir y de poner nombre a las realidades para él exóticas ${ }^{16}$. Hay demasiado

13. Fue grande la influencia de Decroly en América Latina, especialmente Colombia y Costa Rica. Así se se deduce de cantidad de artículos sobre él en Repertorio Americano, la revista latinoamericanista de García Monge. Un trabajo mío al respecto obra en poder del Programa de Identidad, de la Facultad de Letras, UCR, Costa Rica.

14. Ver mi contribución académica «Una generación única de profesionales ticos, formados en Bélgica», Herencia (San José, Costa Rica, volumen 7-8, no 1-2, 1995-96) 15-26. En los años veinte los costarricenses que estudiaban en universidades belgas rozaban el centenar. 15. En la novela hay unas pocas y pequeñas referencias a José Arcadio como estudiante en Roma (p. 396, 405, 407, etc. en mi edición). Es un caso paralelo al del médico que figura en la novela Los Peor, de Fernando Contreras (San José, Farben: 1995).

16. Luis Felipe González, Historia de la influencia extranjera en el desenvolvimiento educacional y cientítico de Costa Rica, editado por primera vez en 1921 y reimpreso después por la Editorial Costa Rica, 1976. Ver particularmente la p. 294, respecto de la labor de los profesores E. De Wildeman y C. Da Candolle y su descripción de la flora costarricense en publicaciones belgas. 
parecido entre vida real y ficción novelesca respecto de Colombia y Costa Rica, en los años antes de la Segunda Guerra, como para que todo sea considerado pura coincidencia.

Según el postulado, nada resulta gratuito o insignificante. Los textos (literarios o históricos), conviene leerlos en su contexto y al revés. Si García Márquez echó mano con tanta insistencia a una serie de interferencias con Bélgica y explota durante por lo menos un octavo del total de páginas de su obra el curioso caso de un flamenco aterrizado en Macondo, no reduce en nada su capacidad creativa el hecho de subrayar que todo eso lo saca de algún lado y que los nexos de estudios entre los dos países no son puro cuento. Respecto de la bicicleta, entre el pueblucho literario y la biografía real de Gabo hay sugestivas pistas que llevan de uno al otro y entre estos y otro pequeño país en Europa. A partir de eso sería completamente absurdo sacar «conclusiones» en cuanto al grado de simpatía o importancia que el Nóbel de literatura de 1982 le dio (o le da) a «Bélgica», mejor dicho a una imagen recreada de ella en los años veinte. Se trata de una visión del otro, desde fuera, hasta con errores evidentes para un decodificador belga: es poco verosímil, ahora y en las primeras décadas del siglo que un flamenco se llame Gastón y que además saque su título en Lieja, Universidad francófona. Pero lo indiscutible es que esta nación, como ninguna otra, ocupa un lugar preponderante en la construcción narrativa de la novela colombiana en cuestión.

\section{Lo real maravilloso en acción}

Al decidirse a publicar su novela, García Márquez tenía tres propósitos: contar alg@, hacerlo de cierta manera y con algún propósito. Queda evidenciado ya que no por falta de imaginación, sino todo lo contrario por constructiva evocación metafórica llena de una creatividad que le envidiamos todos, quiere contar una historia muy parcecida a la de su país y su gente. Esto presupone una relación privilcgialar con Bćlgica, cosa que tampoco permite decir que las 
referencias a este país son imprescindibles en el relato. Lo que quiere demostrar aquí es que las diversas alusiones a este país cuadran perfectamente dentro de la elaboración del realismo maravilloso en esta novela. Respecto de este recurso estilístico, muchos comentaristas han rastreadola importancia de la infancia y la juventud del literato. El hecho de que fuera hijo único criado en el campo por los abuelos y rodeado de mujeres, dejó una huella indeleble ${ }^{17}$. Facundo Cabral alude jocosamente a la abuelita de Gabo, la cual señalaba que este no inventó nada, sino que todo se lo contaron. La ventaja es que el mozuelo tenía muy buena memoria. De este modo, el nexo entre la vida y la creación artística se explicita. Pero hay más. Señala Fernand Braudel que «la simple crónica cotidiana, que no tiene nada de singular y que se reproduce sin escándalo, puede ser el indicador de una realidad perdurable y, a veces, maravillosamente, de una estructura» ${ }^{18}$. He allí la clave: la evocación de tanto hecho aparentemente ridículo, imposible e intrascendente, por acumulación y por disposición en el tiempo, con un código literario de por medio, lleva a una perspectiva ya no de detalle superficial, sino de eje profundo.

Para lo anterior, el novelista partió de su natural percepción de la realidad cotidiana pero, intuitivamente o con cálculo, recurrió además a un proceso constructivo, con un énfasis y una selección de datos. En eso, no hizo más que seguir a sus maestros españoles ${ }^{19}$. En

17. En su biografía de Márquez Dasso Saldívar, atribuye la magia del Nóbel tanto a la influencia de la realidad de Colombia como a la suerte de haber tenido dos abuelitos que le contaban, cada uno a su modo y en su registro, y, en tercer lugar, al hecho privilegiado de que el autor «es un gran vampiro y una esponja que sabe chupar aquello que le aporta cada persona o cada situación», El viaje a la semilla. Biografía de García Márquez (Madrid, Alfaguara: 1977).

18. De una entrevista en Le Monde (París, 14 de octubre de 1979).

19. Se recalca demasiado la importancia de Faulkner en Cien años de soledad: García Márquez mismo reconoce que cuando concibió su novela no conocía al novelista norteamericano: ver en la introducción a mi edición, de mano de Joaquín Marco, p. 24. A mi modo de ver conviene rastrear todavía más a fondo las influencias europeas en esta novela. Si la relación con el Quijote se observa hasta en la presencia estructural de los manuscritos, la influencia de la técnica artística, como en Valle-Inclán, me parece menos estudiada. 
efecto, con la narración sistemática de «tonterías» de pueblo, su barbero, el cura, un escudero etc., Cervantes logró algo más que una ramplonería caballeresca de moda. A propósito deformó aun más la realidad (o las narraciones existentes), llevando muchos elementos a extremos. Un par de siglos después Valle-Inclán, acordándose también de Quevedo, se puso adrede a percibir en el espejo cóncavo. En América Latina el émulo de todos ellos se llama García Márquez.

Consecuente con lo anterior prevalece la voluntad de elaborar un cuadro completo, exagerando sus rasgos, para provocar la reacción del receptor. No voy a retomar aquí los razonamientos teóricos acerca del origen de lo real maravilloso. García Márquez y Carpentier señalan no tener necesidad de inventar ${ }^{20}$ : basta con observar la realidad. Esta, en sí, resulta real y maravillosa. Como queda demostrado, la incidencia de tanta alusión a Bélgica no parte entonces en primera instancia sólo de una escogencia deliberada del autor. Arranca en un hecho comprobado en la misma historia, en la misma circunstancia en que le tocó vivir: la existencia en su tierra de tanto estudioso en aquellas tierras que también pertenecían al imperio donde no se ponía el sol. Todo lo cual a lo mejor en parte, le hizo incluir a Gabo, en su gira europea de los años cincuenta, un país donde la bicicleta es, casi, parte integral de la manera de ser.

El creador de Cien años de soledad quiso evocar el tremendo choque entre las tendencias ancestrales de su pueblo y la renovación que se imponía desde fuera. Es la tensión permanente entre identidad y alienación. Para evocar aquello, en su engranaje demostrativo, le viene de perlas recurrir en tantas cuartillas a las «locuras» de una pareja, con un componente europeo (Gastón) y el otro autóctono (Amaranta Ursula). Los amoríos entre la pareja belga-colombiana pueden verse entonces a nivel superficial, como ocurre al leer el

20. Recomicndo especialmente la lectura de dos clásicos de estos maestros del género:

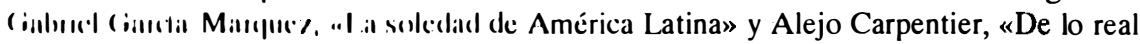

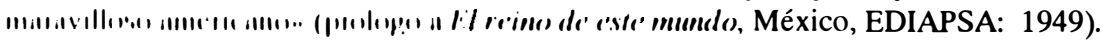


Quijote, viendo sólo las barbaridades de un caballero chiflado, en un entorno cuerdo. Pero las apariencias no lo son todo; la cosa se pone al revés, o mejor dicho, ni el personaje ni su entorno son «normales», sino productos de sus culturas. Recuerdan la pugna entre el allá y el acá que encontramos también en Carpentier (estructuralmente en su obra; vitalmente en su biografía), sólo que captada aquí, desde la estética del fondo del vaso. Ya lo decía Max (Valle-Inclán): la deformación deja de serlo si es sistemática.

En realidad, al final entre la pareja se estableció un típico cruce que uno observa en matrimonios mixtos, con latinoamericana: él se dejó convencer para cruzar el Atlántico y mostró mucha facilidad en el salto transcultural. Sobre una base de experimentación racional aprendida en Europa, con sus experimentos continuos en el trópico casi termina mereciendo el apellido Buendía. ¡Qué diferente lo que pasó con su esposa! Esta no habría podido incorporarse en Europa, pese a que, después en el Caribe, «estaba suscrita a cuanta revista de modas, información artística y música popular se publicaba en Europa». El asimiló en profundidad la lengua, los hábitos culinarios y demás de su tierra de adopción, pero frente a la fuerza envolvente del medio buscó finalmente cómo recuperar su identidad y retomó la distancia. Se salvó de la soledad existencial de los Buendía ahogada en desenfreno pasional, violencia y hasta incesto, formas de relación humana marcadas por el irrespeto al otro. Ella, después de un barniz cultural europeo, se dejó vencer por el torbellino que llevaba en las venas.

Entre otros con la utilización literaria de alusiones a Bélgica, Cien años de soledad, a algo más de treinta años de publicada, sigue siendo una portentosa llamada a la búsqueda de identidad. Constituye una compleja estructuración simbólica del destino de una o más personas, de toda una nación o de toda una civilización, puestos en relación con corrientes externas. Se trata de la misma tensión cultural evocada recientemente en la teoría de Huntington ${ }^{21}$, según el cual las

21. Samuel Huntington, The Clash of Civilizations and the Remaking of World Order (Simon \& Schuster, New York, 1966). 
luchas futuras ya no tendrán origen en lo nacional o lo ideológico, sino en la confrontación cultural. Nuestros literatos de lo real-maravilloso, con su fino olfato, hace tiempo ya se habían adelantado a esas elucubraciones. Lo cual prueba la utilidad del arte como instrumento de percepción y su función de «concientización»: en términos de Skármeta, para los latinoamericanos esta novela es como «la Segunda independencia» ${ }^{22}$. En realidad, en todas partes adquiere un tremendo valor de desenmascaramiento. Confiamos que en el próximo milenio la lectura de este nuevo Quijote seguirá por ambos lados del Atlántico y más allá: también el arte se teje en una telaraña mundial.

22. Ver las declaraciones de este autor retomada en El País, Madrid, 12 de setiembre de 1997, dentro de un artículo “llomenaje a García Márquez en la Universidad de Georgetown», escritor por Javier Vialcristicla. 